\title{
Bis(hexamethylene)triamine as Potential Shale Inhibitor in Water-Based Drilling Fluid
}

\author{
Hanyi Zhong*, Zhengsong Qiu, Weian Huang, Binqiang Xie and Weiji Wang
}

School of Petroleum Engineering, China University of Petroleum, Qingdao, 266580, China

\begin{abstract}
Based on the rules of designing high performance shale inhibitors, bis- (hexamethylene)- triamine was introduced as a potential shale inhibitor in water-based drilling fluid. The inhibitive properties were evaluated through bentonite inhibition test, cuttings hot-rolling dispersion test and particle distribution measurement. The compatibility with common drilling fluid additives was investigated. Bis- (hexamethylene)- triamine effectively inhibited shale swelling and dispersion, superior to potassium chloride and polyetherdiamine POP230, and was compatible with normal additives in drilling fluid. The inhibitive mechanism was analyzed via XRD, zeta potential measurement, FT-IR, water adsorption test and TGA. The results showed that electrostatic interaction, hydrogen bonding and hydrophobic shielding effect contributed to the inhibition with synergetic effects, whereas the protonation of multi-amine groups played a vital role in the action.
\end{abstract}

Keywords: Clay hydration, shale inhibitor, bis(hexamethylene)triamine, property mechanism.

\section{INTRODUCTION}

In the drilling process, borehole stability problems such as bit balling, disintegration of cuttings, borehole wash-out and stuck pipe mostly occur in shale formations due to shale hydration and swelling [1-3]. Oil-based drilling fluids exhibit outstanding inhibitive performance because of the inherent advantages of excluding water from the wellbore. However, the increasingly stringent environmental requirements restrict their wide application. Therefore, tremendous researches have been carried out to develop an environment friendly water-based drilling fluid with performance similar to those of oil-based drilling fluids. Over the past years, many solutions have been proposed to inhibit clay hydration and dispersion through a variety of mechanisms, such as inorganic salts of potassium chloride and sodium chloride, formates, polymers, asphaltenes, sugars and sugar derivatives, polyglycerols and glycols, silicates [4-7]. However, these approaches bring only marginal success [8]. Among these solutions, $\mathrm{KCl}$ with high concentration probably is the mostly applied solution due to its effective inhibition performance. Nevertheless, the high concentration salts adversely affect the environment and logging. Thus, the industry searches for other alternative options that promise to be effective inhibitors of shale swelling, with their abilities to rival with potassium based salts. Then nitrogen-centered derivatives such as amine compounds are developed $[9,10]$. Low molecular weight polyetheramines are introduced as clay swelling inhibitors and considered to be the current best available technology to inhibit shale hydration [11-13]. Based on this polyetheramine, high performance water-based

*Address correspondence to this author at the School of Petroleum Engineering, China University of Petroleum, Qingdao, 266580, China; Tel: 0086-532-86981705; Fax: 0086-532-86981936;

E-mail: zhonghanyi@126.com drilling fluids have been developed and applied successfully around the world [14-17].

With the development of molecular modeling techniques in recent years, the combination of molecular simulation and experimental study offers an improved insight into clay swelling inhibition and a better understanding of the underlying mechanisms at the molecular level, which also assist in the design and improvement of more environmentfriendly clay swelling inhibitors. With a range of computational techniques and, well-known experimental results, a "rule-based" criteria for designing clay-swelling inhibitors has been established $[18,19]$. According to the criteria which illustrates the structural characteristics high performance inhibitors must possess, a low molecular weight compound, bis(hexamethylene) triamine (BHMT), is introduced as a potential clay hydration inhibitor. The inhibitive properties were evaluated through bentonite inhibition test, cuttings hot-rolling dispersion test and particle distribution measurement, and the compatibility with common additives in drilling fluid was investigated. Meanwhile, the inhibitive mechanism was investigated via several methods, including XRD, zeta potential measurement, FT-IR, water adsorption test and TGA.

\section{EXPERIMENT}

\subsection{Materials}

The sodium montmorillonite (Na-MMT) SD-1005 was obtained from Zhejiang Sanding Technology Co., LTD. The chemical compositions of the sample were: $\mathrm{SiO}_{2}, 64.07 \%$; $\mathrm{Al}_{2} \mathrm{O}_{3}, 19.11 \%$; $\mathrm{CaO}, 4.48 \%$; $\mathrm{MgO}, 3.61 \% ; \mathrm{Na}_{2} \mathrm{O}, 3.07 \%$; $\mathrm{Fe}_{2} \mathrm{O}_{3}, 2.64 \% ; \mathrm{P}_{2} \mathrm{O}_{5}, 1.71 \% ; \mathrm{K}_{2} \mathrm{O}, 0.72 \%$. The cationic exchange capacity was $95 \mathrm{mmol} / 100 \mathrm{~g}$ measured by the ammonium acetate method. Drilling fluid bentonite was provided by Weifang Huawei Bentonite Group Co., Ltd, 
China, according to the API standard. Bis(hexamethylene) triamine (BHMT) was purchased from Tokyo Chemical Industry Co., LTD, with the chemical formula of $\mathrm{H}_{2} \mathrm{~N}\left(\mathrm{CH}_{2}\right)_{6}$ $\mathrm{NH}\left(\mathrm{CH}_{2}\right)_{6} \mathrm{NH}_{2}$. Polyetherdiamine (POP230), with the chemical formula of $\mathrm{H}_{2} \mathrm{NCH}\left(\mathrm{CH}_{3}\right) \mathrm{CH}_{2}\left[\mathrm{OCH}_{2}\left(\mathrm{CH}_{3}\right) \mathrm{CH}\right]_{2.6} \mathrm{NH}_{2}$, was obtained from Huntsman Chemical Co., USA. $\mathrm{KCl}$ was provided by Sinopharm Chemical Reagent Co., Ltd, China. All the reagents were used without further purification.

\subsection{Methods}

\subsubsection{Bentonite Inhibition Test}

$400 \mathrm{~mL}$ of water containing $12 \mathrm{~g}$ inhibitor was treated by $5 \mathrm{w} / \mathrm{v} \%$ drilling fluid bentonite. After stirring for $30 \mathrm{~min}$, the dispersion was hot rolled at $70^{\circ} \mathrm{C}$ for $16 \mathrm{~h}$. Then the rheological properties were measured after the samples were cooled to the room temperature. After that the equivalent amount of drilling fluid bentonite was added and the procedure was repeated until the dispersion became too viscous to be measured.

\subsubsection{Cuttings Hot-Rolling Dispersion Test}

$350 \mathrm{~mL}$ of solution with inhibitors of various concentrations and $50 \mathrm{~g}$ of shale cuttings $(2-5 \mathrm{~mm})$ obtained from the upper layer of Shahejie formation in Dagang oil field were added into sealed cells. After hot rolling at $77^{\circ} \mathrm{C}$ for $16 \mathrm{~h}$, the cuttings were washed with $10 \% \mathrm{KCl}$ solution and screened through 40-mesh sieve. The recovered cuttings were dried at $105^{\circ} \mathrm{C}$ for 4 hours and the percentage of recovery was determined.

\subsubsection{Particle Distribution Test}

4w/v\% Na-MMT dispersion was prepared and prehydrated for 24 hours. Inhibitors with certain concentrations were added into the dispersion and stirred vigorously for 24 hours. Then the size distribution of the particles was measured with Rise-2006 laser particle size analyzer (Jinan Runzhi Technical Company, China).

\subsubsection{Interaction Between Na-MMT and BHMT}

BHMT with a range of concentrations was added into $2 \mathrm{w} / \mathrm{v} \%$ prehydrated Na-MMT dispersions and shaken for 24 $\mathrm{h}$ to reach adsorption equilibrium. The dispersion was centrifuged and washed with deionized water several times. One part of the sediment was prepared for XRD measurements directly. The other part was dried at $105^{\circ} \mathrm{C}$ and ground to powders for XRD measurements, FT-IR analysis, water adsorption test and TGA. The powders were pressed into $\mathrm{KBr}$ pellets for FT-IR analysis. FT-IR absorption was recorded by a NEXUS FT-IR spectrometer (Thermo Nicolet Corporation), scanning from 4000 to $400 \mathrm{~cm}^{-1}$, with a $4 \mathrm{~cm}^{-1}$ resolution in transmission. The test procedure of zeta potential was reported previously and measured at room temperature using the Zetasizer 3000 electric potential and granularity meter (Malvern instrument, United Kingdom) [20]. The water adsorption test is shown as follows, $1 \mathrm{~g}$ of modified MMT powders was placed in a sealed glass desiccator with water at the bottom. The amount of water adsorbed was calculated from the mass gain. XRD analysis was performed by using an X'pert PRO MPD diffractometer with $\mathrm{Cu}$ target at a generator voltage of $45 \mathrm{kV}$, current of 50 $\mathrm{mA}$. Samples were measured scanning $2 \theta$ angle from $2^{\circ}$ to $15^{\circ}$. The basal spacing was analyzed by using Bragg's equation. The value for $n=1$ is calculated from $2 d \sin \theta=n \lambda$. Thermal gravimetric analysis (TGA) was performed on a WCT-2D (Beijing Optical Instrument Factory) instruments thermal analyzer at a scan rate of $20^{\circ} \mathrm{C} / \mathrm{min}$ under nitrogen flow. The surface tension of aqueous solution was measured at $25^{\circ} \mathrm{C}$ with DCAT21 surface/interface tensiometer (Beijing Eastern-Dataphy Instruments Co., Ltd).

\section{RESULTS AND DISCUSSIONS}

\subsection{Inhibitive Properties Evaluation}

\subsubsection{Bentonite Inhibition Test}

The test was designed to simulate the relatively slow incorporation of yielding clays into a drilling fluid. This simulated process usually happens when drilling active shales in the field. As shown in Fig. (1), the apparent viscosity (Fig. 1a) and yield point (Fig. (1b) increased sharply with the addition of bentonite in fresh water system due to the hydration and dispersion of clay. On the contrary, the apparent viscosity and yield point increased slowly in the inhibitor systems. Comparing to POP230 and $\mathrm{KCl}$, the lower rheological profile of BHMT proved that it performed a better inhibitive capacity.

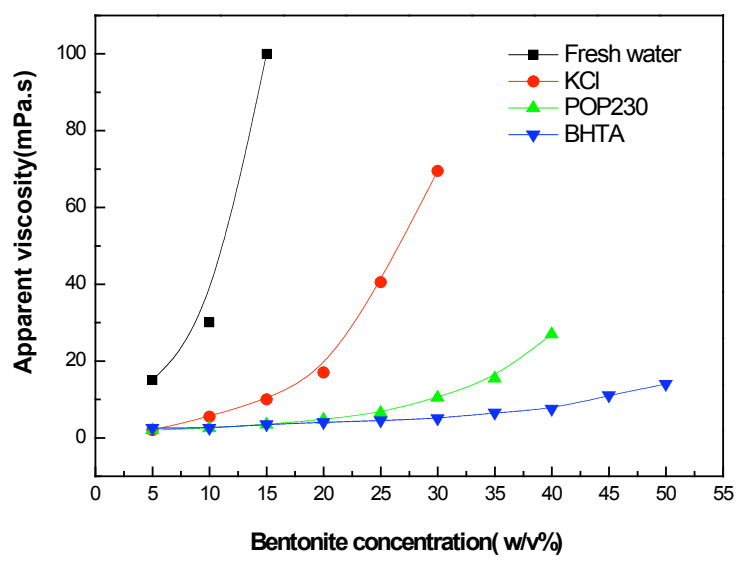

(a)

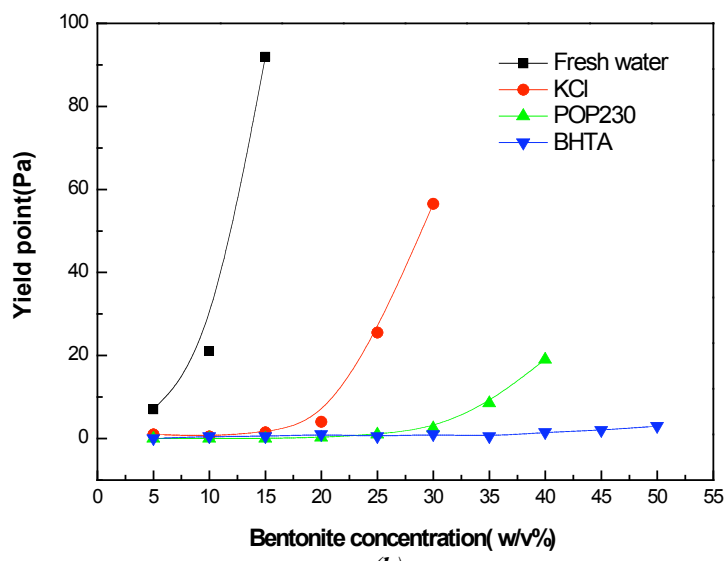

(b)

Fig. (1). Bentonite inhibition test comparing the rheological profile of different shale inhibitors $(3 \% \mathrm{w} / \mathrm{v})$ with the base fluid. Note: (a) Apparent viscosity; (b) Yield point.

\subsubsection{Cuttings Hot-Rolling Dispersion Test}

For cuttings hot-rolling dispersion test, higher recovery and lower dispersion indicated better shale inhibition. 
BHMT and POP230 exhibited excellent inhibitive properties, and the cuttings recovery was increased from $40.7 \%$ to $84.3 \%$ and $80.1 \%$ respectively at the concentration of $0.5 \mathrm{w} /-$ $\mathrm{v} \%$ (Fig. 2). At higher loadings the cuttings recovery changed little. In the case of $\mathrm{KCl}$, the cuttings recovery increased almost linearly with the increasing concentration. When the concentration was $7 \mathrm{w} / \mathrm{v} \%$, the recovery was $79.5 \%$. It can be seen that, BHMT and POP230 effectively reduced the dispersion of shale with relatively low concentration, superior to $\mathrm{KCl}$. Fig. (3) illustrated the cuttings recoveries at various temperatures. $\mathrm{In} \mathrm{KCl}$ solution system, the recovery decreased greatly with increasing temperature, when the temperature was as high as $200^{\circ} \mathrm{C}$, the recovery was reduced from $79.5 \%$ to $58.3 \%$. For BHMT and POP 230 , the cuttings recovery was dropped from $89.6 \%$ to $77.6 \%$ and $85.2 \%$ to $72.1 \%$ respectively. Generally, high temperature promotes the hydration and dispersion of shale and results in thermal degradation of polymer molecules. The two effects contribute to the decrease of cuttings recovery. However, the cuttings recovery was still high for BHMT and POP230 at high temperatures, indicating that BHMT and POP230 are high temperature resistant.

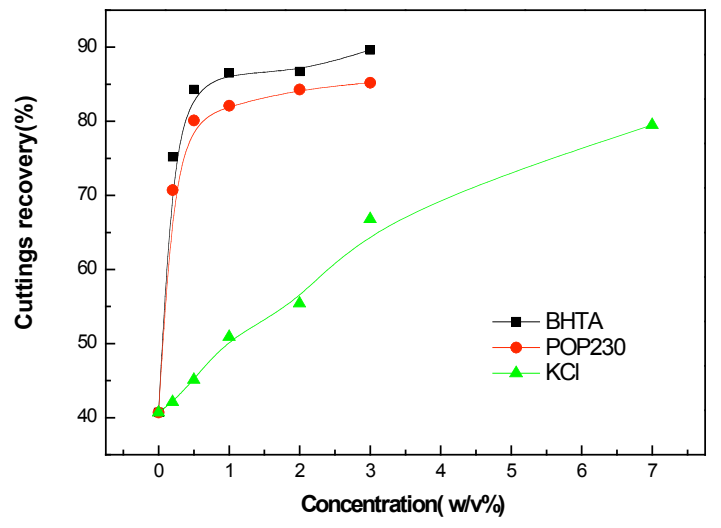

Fig. (2). Cuttings recovery of various inhibitor systems.

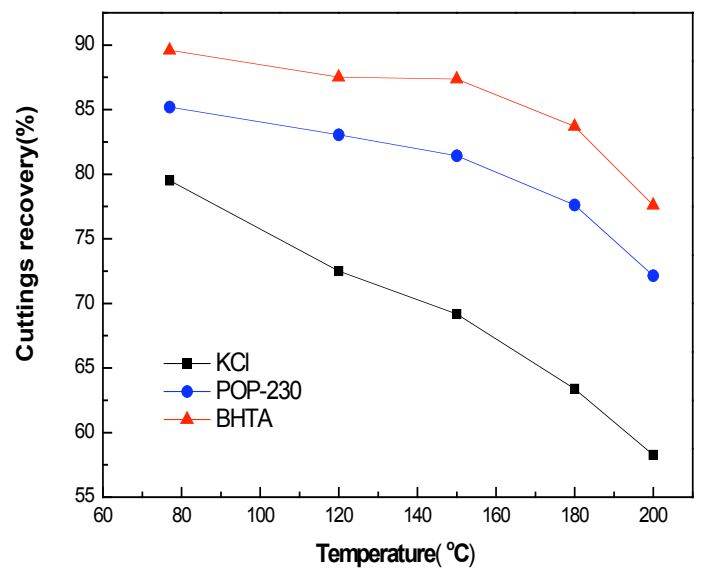

Fig. (3). Cuttings recovery of different temperatures.

\subsubsection{Particle Size Distribution Test}

Fig. (4) depicts the differential distribution (Fig. 4a) and cumulative distribution (Fig. 4b) curves of the Na-MMT dispersions treated with $3.0 \mathrm{w} / \mathrm{v} \% \mathrm{KCl}, 0.5 \mathrm{w} / \mathrm{v} \%$ POP 230 and $0.5 \mathrm{w} / \mathrm{v} \%$ BHMT, respectively. Compared to the sample without inhibitor, the average size of Na-MMT particle was
$1.46 \mu \mathrm{m}$, and the specific surface area was $4.95 \mathrm{~m}^{2} / \mathrm{cm}^{3}$. The addition of inhibitor changed the particle size with the sequence of $\mathrm{KCl}<\mathrm{POP} 230<\mathrm{BHMT}$, with the average particle size of $43.93,50.06$ and $75.76 \mu \mathrm{m}$ and the specific surface area of $0.16,0.14$ and $0.10 \mathrm{~m}^{2} / \mathrm{cm}^{3}$ respectively. The larger particle size and less specific surface area reduced the sensibility of the clay minerals to water. BHMT was more effective than $\mathrm{KCl}$ and POP230 in inhibiting clay hydration and swelling.

\subsection{Compatibility Test}

Several traditional additives including anionic and nonionic polymers were selected to verify their compatibility with BHMT. Pure polymer solutions were prepared with deionized water at concentration of $0.5 \mathrm{w} / \mathrm{v} \%$. Equivalent amount of BHMT was added into the solution and stirred for 30 minutes. Then the rheological properties were measured. As shown in (Table 1), the apparent viscosity, plastic viscosity and yield point changed a little in solutions of polyanionic cellulosic polymer with high viscosity (PAC-H), xanthan gum (XC), amphoteric polymer encapsulator (FA367), par-tially hydrolyzed polyacrylonitrile (PHPA) and Polyacryl-amide (PAM) after BHMT addition, neither apparent preci-pitation was observed, indicating that BHMT was compati-ble with these additives.

For amine compounds, dissociation equilibrium exists when dissolved in water, which is as follows,

$$
\mathrm{RNH}_{2}+\mathrm{H}_{2} \mathrm{O} \rightleftharpoons \mathrm{RNH}_{3}{ }^{+}+\mathrm{OH}^{-}
$$

Because of the alkalescent property of the amine compounds, when dissociation equilibrium was reached, the concentration of protonated ammonium ions in solution was relatively low, and intensive interaction between ammonium ions and negative charged polymers would not occur. Therefore favorable compatibility was observed between BHTM and common polymer additives used in drilling fluid.

\subsection{Inhibitive Properties Analysis}

\subsubsection{XRD Test}

Figs. (5) and (6) compare the XRD patterns of MMT and intercalated by BHMT at various contents with both dry and wet samples. The basal spacing of virgin MMT was $1.25 \mathrm{~nm}$, responding to a typical characteristic of sodium montmorillonite. After intercalation by BHMT at content of 0.002$\mathrm{mol} / \mathrm{L}$, the basal spacing increased to $1.32 \mathrm{~nm}$. Then the basal spacing changed a little irrespective of the increasing concentration, suggesting that BHMT molecules lay parallel to the clay layer forming monolayer arrangement in the gallery of MMT. This tendency was also observed in wet samples. The uptake of water molecules resulted in the dramatic increase of basal spacing as high as $1.87 \mathrm{~nm}$ for pure MMT. The incorporation of BHMT exchanged the hydrated sodium ions and their associated hydration shells, and the positively protonated ammonium ions neutralized the negative charges with multi-sites, pulling or "pining" the adjacent layers together and leading to the collapse of structure with decreased interlayer space of $1.36 \mathrm{~nm}$. Compared with $\mathrm{KCl}$ [21], BHMT reduced the interlayer space with relatively lower concentration and reduced the interlayer space to the minimum. Because of multi-sites adsorption, it is difficult for BHMT to desorb from clay surface, therefore it can stabilize clay for a long time effect. 

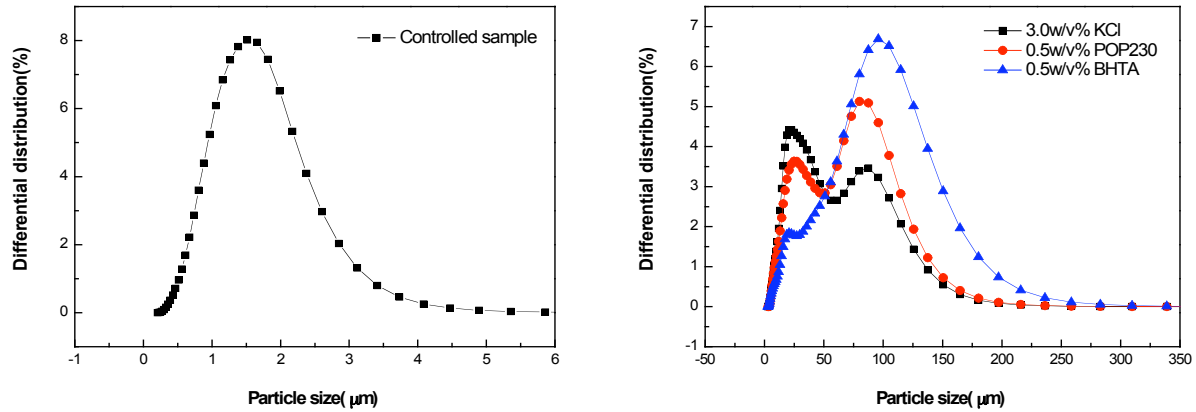

(a)
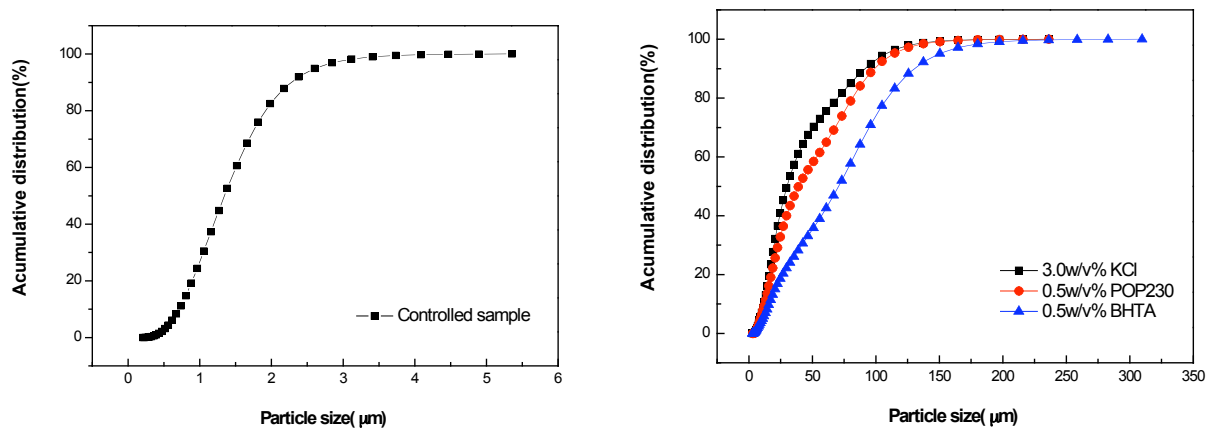

(b)

Fig. (4). Effect of inhibitors on particle size distribution of montmorillonite with various concentrations. Note: (a) Differential distribution; (b) Cumulative distribution.

Table 1. Compatibility of BHMT with Common Additives in Drilling Fluid

\begin{tabular}{|c|c|c|c|}
\hline Sample & AV(mPa.s) & PV(mPa.s) & $\mathbf{Y P}(\mathbf{P a})$ \\
\hline $0.5 \mathrm{w} / \mathrm{v} \% \mathrm{PAC}-\mathrm{H}$ & 25 & 16 & 9 \\
\hline $0.5 \mathrm{w} / \mathrm{v} \% \mathrm{PAC}-\mathrm{H}+0.5 \mathrm{w} / \mathrm{v} \% \mathrm{BHMT}$ & 25.5 & 16 & 9.5 \\
\hline $0.5 \mathrm{w} / \mathrm{v} \% \mathrm{XC}$ & 29.5 & 15 & 14.5 \\
\hline $0.5 \mathrm{w} / \mathrm{v} \% \mathrm{XC}+0.5 \mathrm{w} / \mathrm{v} \% \mathrm{BHMT}$ & 29 & 15 & 14 \\
\hline $0.5 \mathrm{w} / \mathrm{v} \% \mathrm{FA} 367$ & 14 & 9 & 5 \\
\hline $0.5 \mathrm{w} / \mathrm{v} \% \mathrm{FA} 367+0.5 \mathrm{w} / \mathrm{v} \% \mathrm{BHMT}$ & 13.5 & 9 & 4.5 \\
\hline $0.5 \mathrm{w} / \mathrm{v} \% \mathrm{PHPA}$ & 5 & 4 & 1 \\
\hline $0.5 \mathrm{w} / \mathrm{v} \% \mathrm{PHPA}+0.5 \mathrm{w} / \mathrm{v} \% \mathrm{BHMT}$ & 5 & 4 & 1 \\
\hline $0.5 \mathrm{w} / \mathrm{v} \% \mathrm{PAM}$ & 10 & 7 & 3 \\
\hline $0.5 \mathrm{w} / \mathrm{v} \% \mathrm{PAM}+0.5 \mathrm{w} / \mathrm{v} \% \mathrm{BHMT}$ & 10 & 8 & 2 \\
\hline
\end{tabular}

\subsubsection{Zeta Potential Measurement}

Fig. (7) shows the effect of the two amine compounds on the zeta potential values of MMT dispersions. The zeta potential value of pure MMT-water dispersion was $-33.4 \mathrm{mV}$. After the addition of $0.2 \mathrm{w} / \mathrm{v} \%$ amine, a sharp increase from 33.4 to $-5.1 \mathrm{mV}$ and -33.4 to $-2.3 \mathrm{mV}$ was observed for POP230 and BHMT respectively. At higher loadings, the zeta potential became less negative. The protonated ammonium ions neutralized the negative charge of clay surface. In other words, the main driving force for the adsorption was electrostatic force. However, over the whole concentration range, no charge reversal was observed, which was attributed to the alkalescent property of the amine [22]. Because of higher ratio of amine groups, BHMT reduced the zeta potential to a higher degree than POP230, resulting in clay particles less water sensitive. The decrease of clay layer charge results in clay less water sensitive. 


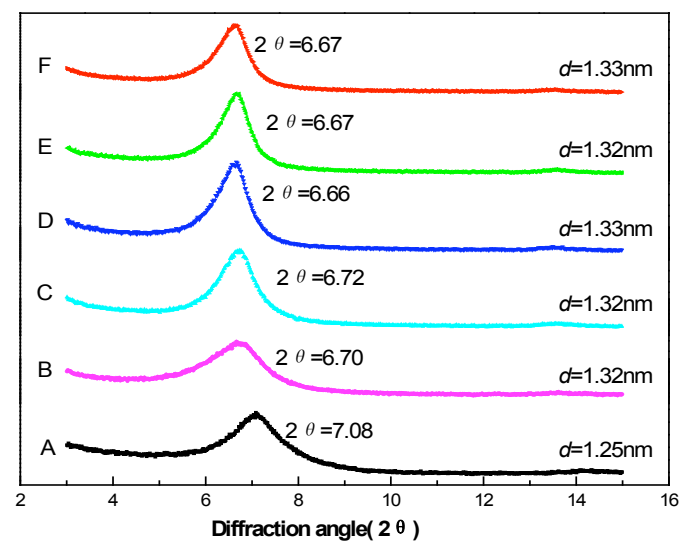

Fig. (5). X-ray diffraction patterns of MMT-BHMT samples at various concentrations (mol/L) with dry sample. Note: (A):0; (B):0.002; (C):0.005; (D): 0.01; (E):0.02; (F):0.05.

\subsubsection{FT-IR Spectra Measurement}

To further confirm the adsorption of BHMT on MMT, FT-IR spectra were measured for pure BHMT, MMT and MMT modified with BHMT (Fig. 8). For MMT, the peaks recorded at 3440 and $1640 \mathrm{~cm}^{-1}$ are attributed to the stretching and bending vibrations of physically adsorbed water on the clay particles, respectively. The appearance of new bands such as 3260, 2940 and $2870 \mathrm{~cm}^{-1}$ in the FT-IR spectrum of MMT modified with BHMT proved the adsorption of BHMT. The adsorption of BHMT showed N-H bending vibrations at $1590 \mathrm{~cm}^{-1}$ with a shoulder at $1650 \mathrm{~cm}^{-1}$, and the characteristic N-H stretching vibrations of $3280 \mathrm{~cm}^{-1}$. After the intercalation of BHMT into the interlayer space, the shift of adsorption at $1590 \mathrm{~cm}^{-1}$ to $1630 \mathrm{~cm}^{-1}$ in the modified composite implied substantial hydrogen bonds occurring. This change of $\mathrm{N}-\mathrm{H}$ bending vibration demonstrated that BHMT intercalated in the interlayer with both protonated and unprotonated $-\mathrm{NH}_{2}$ species [23]. Because amine groups dissociate in aqueous solution, the ratio of protonated ammonium ions to amine groups will reach a dynamic equilibrium, which
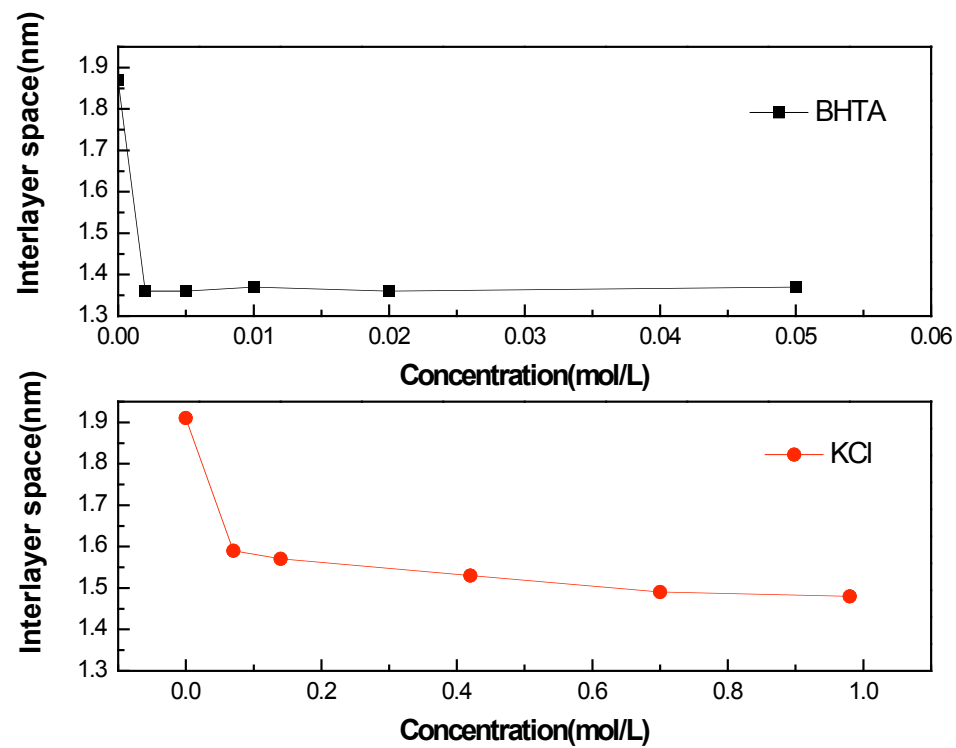

Fig. (6). X-ray diffraction patterns of Na-MMT/BHMT samples at various concentrations with wet sam

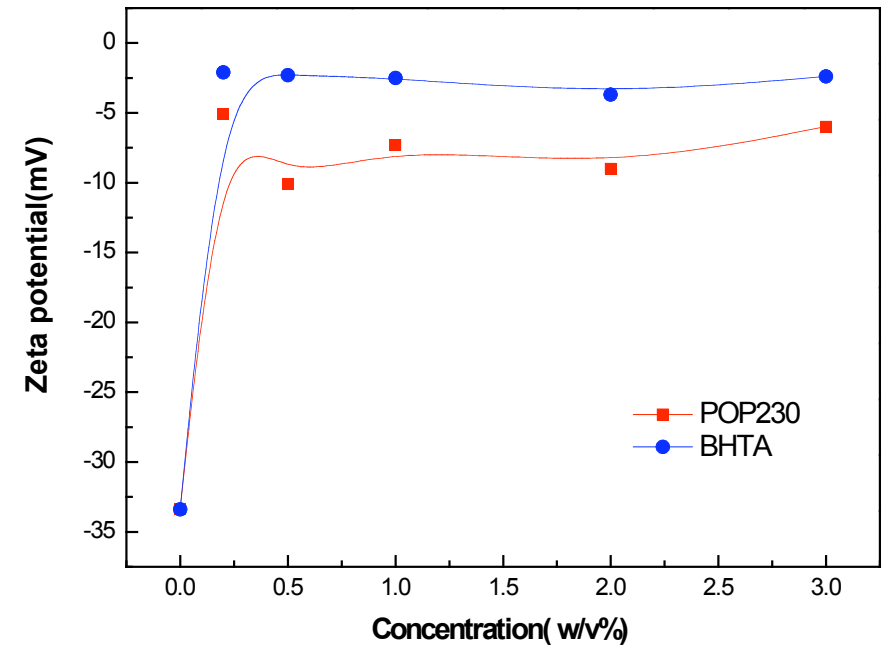

Fig. (7). Zeta potential variations as a function of inhibitor concentrations. 


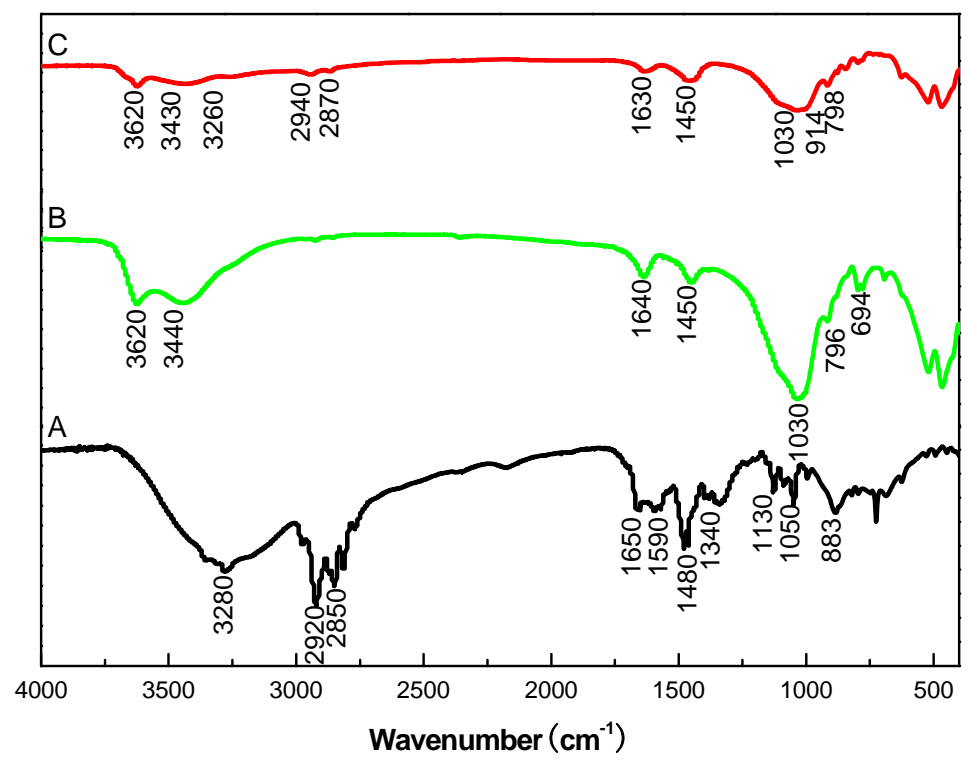

Fig. (8). Comparisons of FT-IR results. Note: (A) pure BHMT; (B) MMT; (C) MMT-BHMT

depends on the $\mathrm{pH}$ value, concentration and so on. Ammonium ions can establish several hydrogen bonds with oxygen atoms from the surface of the clay mineral layers [24]. Thus, it could be assumed that, except for electrostatic interaction, hydrogen bonding between amine group and siloxane of clay existed in the interlayer, which may further restrict the swelling and hydration of clay minerals.

\subsubsection{Water Adsorption Test}

Displacement of inorganic exchangeable cations by organic cations renders the bentonite from hydrophilic to hydrophobic [25-27]. Hence, water adsorption experiment was performed to characterize the water affinity of bentonite surface after modified by BHMT. Adsorption curves were calculated using the relationship between the amount of water adsorbed and the time. As shown in Fig. (9), the water adsorption rate increased dramatically at the initial 48 hours, followed by slow increase. Compared with virgin MMT, the amount of adsorbed water for modified composite was much lower, indicating that the water affinity of the MMT was reduced after polymer modification. Generally, the higher concentration of the polymer, the lower water adsorption rate was obtained. The water affinity of MMT-BHMT was higher than that of MMT-POP230 when modified with equal concentration, which was attributed to the surface activity difference of the two compounds. BHMT was less surface active compared to POP230 (Fig. 10). The conversion of MMT surface from highly hydrophilic to relatively hydrophobic after polymer intercalation prevented the ingress of water, which was favor of clay stability. Although BHMT exhibited less surface activity and changed the MMT surface less hydrophobic, the above inhibitive evaluation experiments indicated that BHMT was superior to POP230 in inhibiting the hydration and swelling of clay. Electrostatic force dominated in the hydration inhibition action, whereas the hydrophobic effect played a smaller and compensating role.

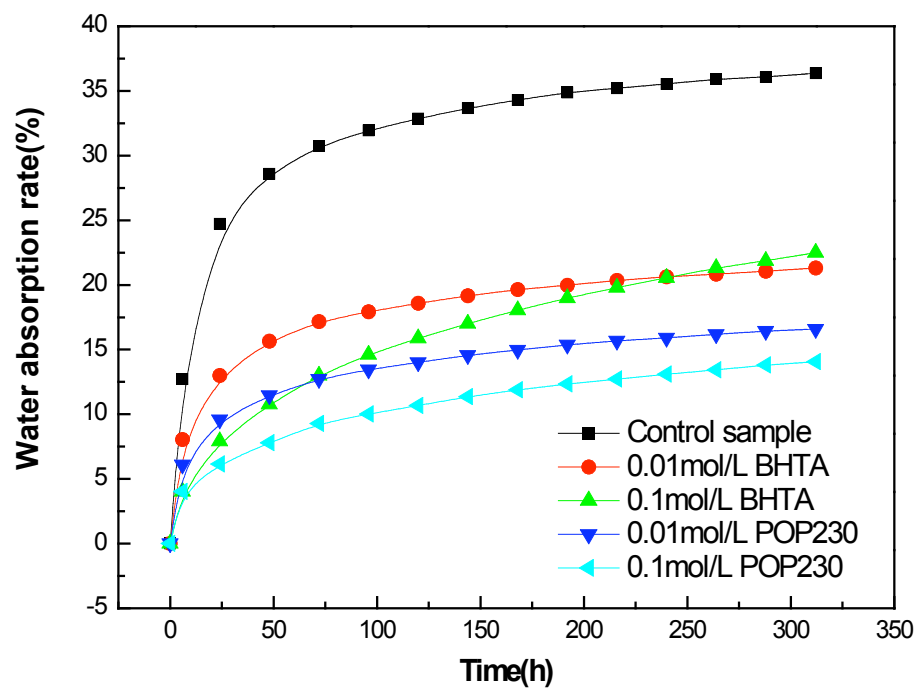

Fig. (9). Water adsorption rate as a function of time 


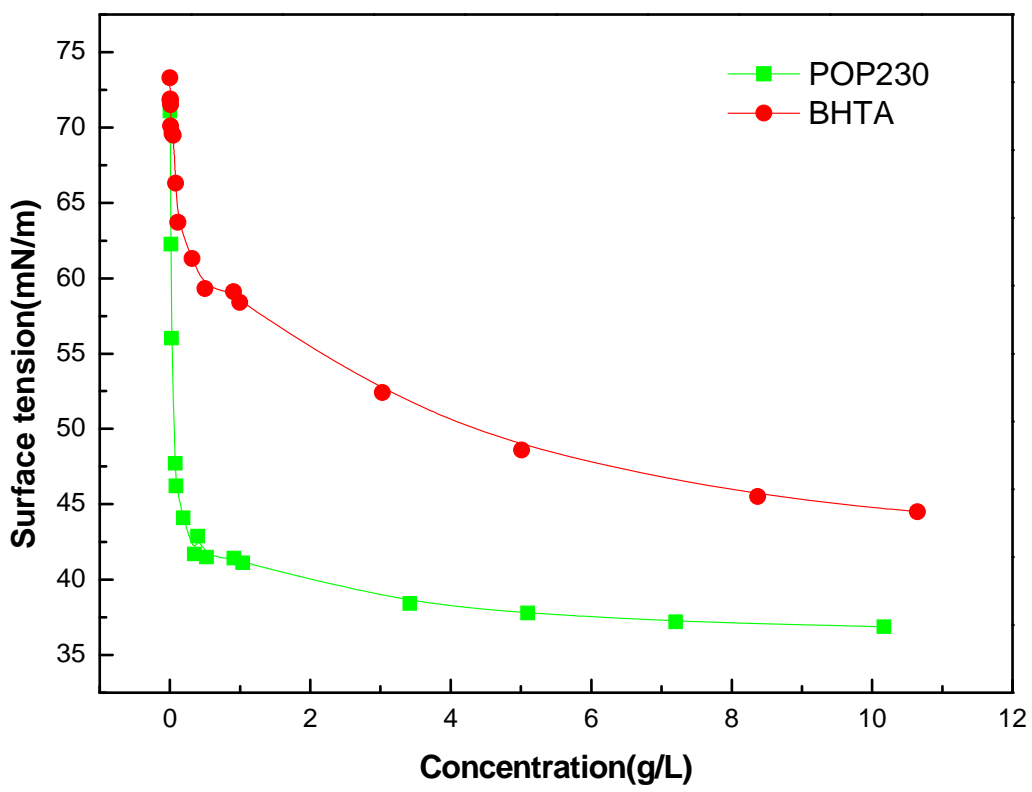

Fig. (10). Surface tension as a function of concentration.

\subsubsection{TGA Analysis}

Thermogravimetric analysis was used to probe the thermal stability of organic clay and the microenvironment of intercalated organic molecules. Generally, several mass loss steps are observed in the process of decomposition of $\mathrm{Na}$ MMT modified by organic compounds [28]. Before $200^{\circ} \mathrm{C}$ the mass loss is assigned to the dehydration of physically adsorbed water and water molecules around metal cations such as $\mathrm{Na}^{+}$and $\mathrm{Ca}^{2+}$ on exchangeable sites in MMT [29]. Therefore in this study, the mass loss below $200^{\circ} \mathrm{C}$ was investigated because water content was of vital importance to clay reactivity. As shown in Fig. (11), from ambient temperature to $200^{\circ} \mathrm{C}$, the weight loss of Na-MMT was $6.35 \%$, while the weight loss of BHMT modified MMT was $0.25 \%$, much lower than that of Na-MMT, indicating that the intercalation of BHMT reduced the water content of montmorillonite, in agreement with the results of XRD patterns of wet samples.

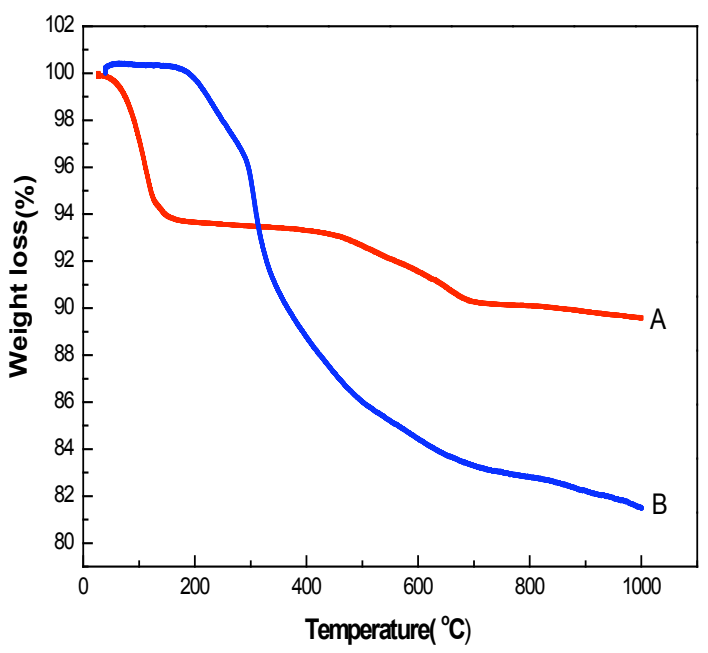

Fig. (11). TGA curves of MMT and MMT modified with BHMT at concentrations of $0.5 \mathrm{w} / \mathrm{v} \%$. Note: (A) Na-MMT; (B) MMT-BHMT.

\section{CONCLUSION}

BHMT was selected as a potential shale inhibitor according to the rules of molecular structure design. The inhibitive evaluation showed that significant reduction in clay hydration and dispersion was obtained by BHMT compared to existing inhibitors. Also BHMT was high temperature resistant and was compatible with other common additives used in water-based drilling fluid. BHMT intercalated into the clay gallery with monolayer arrangement. The positively protonated ammonium ions neutralized the negative sites of clay surface. Meanwhile hydrogen bonds between amine groups and siloxane of clay were formed. The coordination of electrostatic interaction and hydrogen bonding collapsed the hydrated structure of clay minerals. The multi-site adsorption pulled the adjacent layers together and prevented the ingress of water, resulting in a long time effect. The adsorption of BHMT rendered the clay surface more hydrophobic and less affinity to water. However, the hydrophobic shielding effect only played a secondary role in inhibition.

\section{NOMENCLATURE}

$\begin{array}{lll}\text { BHMT } & =\text { Bis-(hexamethylene)- triamine } \\ \text { FA367 } & =\text { Amphoteric polymer encapsulator } \\ \text { FT-IR } & = & \text { Fourier transform infrared spectroscopy } \\ \text { Na-MMT }= & \text { Sodium montmorillonite } \\ \text { PAC-H } & =\text { Polyanionic cellulosic polymer with high } \\ & \text { viscosity } \\ \text { PAM } & =\text { Polyacrylamide } \\ \text { PHPA } & =\text { Partially hydrolyzed polyacrylonitrile } \\ \text { POP230 } & =\text { Polyetherdiamine with molecular weight of } \\ & =230 \\ \text { TGA } & =\text { Thermogravimetric analysis } \\ \text { XC } & = & \text { Xanthan gum } \\ \text { XRD } & = & \text { X-ray diffraction }\end{array}$




\section{CONFLICT OF INTEREST}

The authors confirm that this article content has no conflicts of interest.

\section{ACKNOWLEDGEMENTS}

This work was financially supported by the Fundamental Research Funds for the Central Universities (No.12CX06023A), the Fund of Excellent Doctoral Dissertation Training Project (No.LW110202A) and NSF of China (No. 41072094).

\section{REFERENCES}

[1] R.H. Retz, J. Friedheim, L.J. Lee, and O.O. Welch, "An environmentally acceptable and field-practical, cationic polymer mud system", In: SPE 23064 Prepared for Presentation at the Offshore Europe Conference Held in Aberdeen, September 3-6, 1991.

[2] J.J Sheu, and A.C. Perricone, "Design and synthesis of shale stabilizing polymers for water-based drilling fluids", In: SPE 18033 Prepared for Presentation at the SPE Annual Technical Conference and Exhibition, 2-5 October, Texas, 1988.

[3] E. Stamatakis, C.J. Thaemlitz, G. Coffin, and W. Reid, "A new generation of shale inhibitors for water-based muds", In: SPE/IADC 29406 Prepared for Presentation at the 1995 SPE/IADC Drilling Conference Held in Amsterdam, February 28 March 2, Amsterdam, 1995.

[4] R. Bland, G.L. Smith, P. Eagark, E. Van Oort, and N. Dharma, "Low salinity polyglycol water-based drilling fluids as alternatives to oil-based muds", In: IADC/SPE 36400 Prepared for Presentation at the IADC/SPE Asia Pacific Drilling Technology Conference, September 9-11, Kuala Lumpur, 1996.

[5] W.A. Liao, and D.R. Siems, "Adsorption characteristics of PHPA on formation solids", In: IADC/SPE 19945 Prepared for Presentation at the IADC/SPE Drilling Conference, February 27 March 2, Texas, 1990.

[6] E. Van Oort, "On the physical and chemical stability of shales", Journal of Petroleum Science and Engineering, vol. 38, pp. 213235,2003 .

[7] E. Van Oort, D. Ripley, I. Ward, J.W. Chapman, R. Williamson, and M. Aston, "Silicate-based drilling fluids: competent, costeffective and benign solutions to wellbore stability problems", In: IADC/SPE 35059 Prepared for Presentation at the IADC/SPE Drilling Conference, March 12-15, Louisiana, 1996.

[8] R.G. Bland, R.R. Waughman, P.G. Tomkins, W.S. Halliday, R.C. Pessier, and M.R. Isbell, "Water-based alternatives to oil-based muds: do they actually exist?" In: IADC/SPE 74542 Prepared for Presentation at the IADC/SPE Drilling Conference, February 2628, Texas, 2002

[9] R. Schlemmer, A. Patel, J. Friedheim, S. Young, and B. Bloys, "Progression of water-based fluids based on amine chemistry - can the road lead to true oil mud replacements?" In: AADE-03-NTCE36 Prepared for Presentation at the AADE 2003 National Technology Conference "Practical solutions for Drilling Challenges" held at the Radisson Astrodome, April 1-3, Texas, 2003.

[10] X. Guerrero, M. Guerrero, and B. Warren, "Use of amine/PHPA system to drill high reactive shales in the Orito field in Colombia", In: SPE 104010 Prepared for Presentation at the First International Oil Conference and Exhibition in Mexico held in Cancun, August 31- September 2, Mexico, 2006.

[11] M. Hodder, S. Cliffe, C. Greenwell, P. Williams, and P. Coveney, In: AADE-10-DF-HO-32 Prepared for Presentation at the 2010 AADE Fluids Conference and Exhibition at the Hilton Houston North, April 6-7, Houston, Texas, 2010.

[12] A. Patel, E. Stamatakis, J.E. Friedheim, and E. Davis, "Clay swelling inhibitors- computer design and validation", In: AADE 01NC-HO-55 Prepared for Presentation at the AADE 2001 National Drilling Conference, "Drilling Technology- the Next 100 Years",
Held at the Omni Houston Westside in Houston, March 27-29, Texas, 2001.

[13] S. Young, and E. Stamatakis, "Novel inhibitor chemistry stabilizers shales AADE-06-DF-HO-39", In: Prepared for Presentation at the AADE 2006 Fluids Conference Held at the Wyndam Greenspoint Hotel in Houston, April 11-12, Texas, 2006.

[14] A. Al-Ansari, K. Yadav, S. Aramco, D. Anderson, R. Leaper, W. Dye, and N. Hansen, "Diverse application of unique highperformance water-based-mud technology in the Middle East", In: SPE/IADC 97314 Prepared for Presentation at the SPE/IADC Middle East Drilling Technology Conference \& Exhibition held in Dubai, September 12-14, U.A.E, 2005.

[15] A.D. Patel, "Design and development of quaternary amine compounds: shale inhibition with improved environmental profile", In: SPE 121737 Prepared for Presentation at the 2009 SPE International Symposium on Oilfield Chemistry held in The Woodlands, April 20-22, Texas, 2009.

[16] A. Patel, E. Stamatalis, S. Young, and S. Cliffe, "Designing for the future- a review of the design, development and testing of a novel, inhibitive water-based drilling fluid", In: $A A D E-02-D F W M-H O-33$ Prepared for Presentation at the AADE 2002 Technical Conference, "Drilling \& Completion Fluids and Waste Management", held at the Radisson Astrodome, April 2-3, Houston, Texas, 2002.

[17] S. Young, and G. Ramses, "Drilling performance and environmental compliance- resolution of both with a unique waterbased fluid", In: SPE/IADC 103967 Prepared for Presentation at the 2006 SPE/IADC Indian Drilling Technology Conference and Exhibition held in Mumbai, October 16-18, India, 2006.

[18] R.L. Anderson, I. Ratcliffe, H.C. Greenwell, P.A. Williams, S. Cliffe, and P.V. Coveney, "Clay swelling - A challenge in the oilfield", Earth-Science Reviews, vol. 98, pp. 201-216, 2010.

[19] J.L. Suter, P.V. Coveney, R.L. Anderson, H.C. Greenwell, and S Cliffe, "Ruled based design of clay-swelling inhibitors", Energy \& Environmental Science, vol. 4, pp. 4572-4586, 2011.

[20] H.Y. Zhong, Z.S. Qiu, W.A. Huang, and J. Cao, "Shale inhibitive properties of polyether diamine in water-based drilling fluid", Journal of Petroleum Science and Engineering, vol. 78, pp. 510$515,2011$.

[21] H.Y. Zhong, Z.S. Qiu, W.A. Huang, and J. Cao, "Poly (oxypropylene)-amidoamine modified bentonite as potential shale inhibitor in water-based drilling fluids", Applied Clay Science, vol. 67, pp. 36-43, 2012.

[22] J. Wang, G.P. Liu, L.Y. Wang, C.F. Li, J. Xu, and D.J. Sun, "Effect of polyoxypropylenediamine adsorption on hydration and dispersion of montmorillonite particles in aqueous solution", Colloids and Surfaces A, vol. 353, pp. 117-127, 2010.

[23] H.C. Greenwell, M.J. Harvey, P. Boulet, A.A. Bowden, P.V Coveney, and A. Whiting, "Interlayer structure and bonding in nonswelling primary amine intercalated clays", Macromolecules, vol. 38, pp. 6189-6200, 2005.

[24] M. Gautier, F. Muller, L.L. Forestier, J.M. Beny, and R. Guegan, "NH4-smectite: Characterization, hydration properties and hydro mechanical behaviour", Applied Clay Science, vol. 49, pp. 247-254, 2010.

[25] G. Lagaly, R. Witter, and H. Sander, "Water on hydrophobic surfaces", In: R.H. Ottewill, C.H. Rochester, Eds., Adsorption from solution. Academic Press: London, 1983, pp. 65-77.

[26] R.R. Tiwari, K.C. Khilar, and U. Natarjan, "Synthesis and characterization of novel organo- montmorillonite", Applied Clay Science, vol. 38, pp. 203-208, 2008.

[27] J.X. Zhu, Y.H. Qing, T. Wang, R.L. Zhu, J.M. Wei, Q. Tao, and P Yuan, "Preparation and characterization of zwitterionic surfactantmodified montmorillonite", Journal of Colloid and Interface Science, vol. 360, pp. 386-392, 2011.

[28] Y.F. Xi, Q. Zhou, R.L. Frost, and H.P. He, "Thermal stability of octadecyltrimethylammonium bromide modified montmorillonite organoclay", Journal of Colloid and Interface Science, vol. 311, pp. 347-353, 2007.

[29] Y.F. Xi, Z. Ding, and R.L. Frost, "Structure of organoclays- an Xray diffraction and thermogravimetric analysis study", Journal of Colloid and Interface Science, vol. 277, pp. 116-120, 2004.

(C) Zhong et al.; Licensee Bentham Open.

This is an open access article licensed under the terms of the Creative Commons Attribution Non-Commercial License (http://creativecommons.org/licenses/by-nc/3.0/) which permits unrestricted, non-commercial use, distribution and reproduction in any medium, provided the work is properly cited. 